Check for updates

Cite this: RSC Adv., 2018, 8, 23891

Received 24th May 2018

Accepted 25th June 2018

DOI: $10.1039 / c 8 r a 04452 j$

rsc.li/rsc-advances

\section{Exploring weak intermolecular interactions in thiocyanate-bonded Zn(II) and Cd(II) complexes with methylimidazole: crystal structures, Hirshfeld surface analysis and luminescence properties $\dagger$}

\begin{abstract}
Alejandro Di Santo, ${ }^{a}$ Hiram Pérez, ${ }^{* b}$ Gustavo A. Echeverría, $\$^{c}$ Oscar E. Piro, $\$^{\mathrm{c}}$

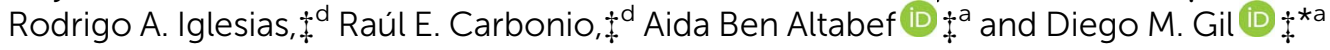

Four new thiocyanate-Zn(॥) and - $\mathrm{Cd}(\Perp)$ complexes with 1-methylimidazole (1-Melm) and 2methylimidazole (2-Melm), namely, Zn(1-Melm) $)_{2}(\mathrm{SCN})_{2}$ (1), $\mathrm{Zn}(2-\mathrm{Melm})_{2}(\mathrm{SCN})_{2}$ (2), Cd(1-Melm) ${ }_{4}(\mathrm{SCN})_{2}$ (3) and polymeric $\left[\mathrm{Cd}(2-\mathrm{Melm})_{2}(\mathrm{SCN})_{2}\right]_{n}(4)$, have been synthesized and characterized by IR, Raman and UV-Vis spectroscopy. The thermal behavior for all complexes was evaluated by thermo-gravimetric analysis and differential thermal analysis. The crystal structures of complexes 1-4 were solved by singlecrystal X-ray diffraction methods. A study of intermolecular interactions in the solid state compounds revealed that molecules are linked by weak $\mathrm{N}-\mathrm{H} \cdots \mathrm{S}$ and $\mathrm{C}-\mathrm{H} \cdots \mathrm{S}$ hydrogen bonds and also by $\mathrm{C}-\mathrm{H} \cdots \pi$ interaction in the case of structures $2-4$, which are responsible for the formation and stability of the molecular assemblies. Hirshfeld surfaces and 2D-fingerprint plots allowed us to visualize the intermolecular contacts and their relative contributions to the total surface for each compound. A comparative analysis against similar halogen-bonded complexes was carried out to investigate the tendency of inter-molecular interactions to form contacts in crystals by using the enrichment ratio descriptor. The emission spectra of the free imidazole derivatives and their $\mathrm{Zn}(\|)$ and $\mathrm{Cd}(॥)$ complexes were recorded in acetonitrile solutions. The emissions observed in the spectra of complexes were ascribed to the intra-ligand transitions and ligand-to-metal charge transfer and we have observed an interesting correlation between the fluorescence intensities and $\mathrm{C}-\mathrm{H} \cdots \pi$ interactions.
\end{abstract}

\section{Introduction}

The design and synthesis of metal complexes with structural diversities such as metal-organic frameworks are topics of great interest for the possible applications in molecular separation,

${ }^{a} I N Q U I N O A$ (CONICET-UNT). Instituto de Química Física. Facultad de Bioquímica, Química y Farmacia, Universidad Nacional de Tucumán, San Lorenzo 456, T4000CAN, San Miguel de Tucumán, Argentina.E-mail:dmgil@fbqf.unt.edu.ar ${ }^{b}$ Departamento de Química General e Inorgánica, Facultad de Química, Universidad de La Habana, Habana 10400, Cuba. E-mail: alinaca@infomed.sld.cu

${ }^{c}$ Departamento de Física, Facultad de Ciencias Exactas, Universidad Nacional de La Plata e IFLP (CONICET, CCT-La Plata), C.C. 1900, La Plata, Argentina

${ }^{d}$ INFIQC (CONICET-UNC), Departamento de Fisicoquímica, Facultad de Ciencias Químicas, Universidad Nacional de Córdoba, Ciudad Universitaria, X5000HUA, Córdoba, Argentina

$\dagger$ Electronic supplementary information (ESI) available. CCDC Any request to the Cambridge Crystallographic Data Centre for these material should quote the full literature citation and the reference number CCDC $1588816\left[\mathrm{Zn}(1-\mathrm{MeIm})_{2}(\mathrm{SCN})_{2}\right]$, CCDC $1588817\left[\mathrm{Zn}(2-\mathrm{MeIm})_{2}(\mathrm{SCN})_{2}\right], \mathrm{CCDC} 1588818\left[\mathrm{Cd}(1-\mathrm{MeIm})_{4}(\mathrm{SCN})_{2}\right]$ and CCDC $1588819\left(\left[\mathrm{Cd}(2-\mathrm{MeIm})_{2}(\mathrm{SCN})_{2}\right]_{n}\right)$. The geometry of the molecules was calculated using Platon for Windows Taskbar v1.17. ${ }^{21}$. The drawings were made with Olex2 (ref. 22) and Mercury. ${ }^{23}$ For ESI and crystallographic data in CIF or other electronic format see DOI: $10.1039 / \mathrm{c} 8 \mathrm{ra04452 \textrm {j }}$

$\$$ Members of the Research Career of CONICET sensing, luminescent materials and nonlinear optical devices, and also in the production of micro-porous materials. ${ }^{1-5}$

Pseudohalides, especially thiocyanate, azide and dicyanamide anions, have attracted attention due to the variety of their bonding modes, including various bridging modes (see Scheme 1 for the thiocyanate ligand). ${ }^{6}$ The observed coordination modes of the $\mathrm{SCN}^{-}$anion are largely influenced by the nature of the co-ligands. The synthesis and structural characterization of thiocyanate-metal(II) complexes using diverse organic ancillaries as co-ligands have been recently reported. ${ }^{7}$ Among them there are a few crystalline complexes with metals of the group 12 and imidazole ligands, which present exclusively conventional hydrogen bonds in their respective supra-molecular assemblies. ${ }^{8,9}$ However, weak intermolecular hydrogen bonds and C$\mathrm{H} \cdots \pi$ interactions in our thiocyanate-linked complexes provide further stability to the crystal structures. In the complexes under study, we have found an interesting correlation between fluorescence and the $\mathrm{C}-\mathrm{H} \cdots \pi$ interactions, indicating that longer values of $\mathrm{H} \cdots \mathrm{Cg}$ (inter-centroid) distances are not significant but in complexes with lower distances, higher fluorescence intensity are obtained. To the best of our knowledge, $\mathrm{C}-\mathrm{H} \cdots \pi$ interactions are not common in the referred 


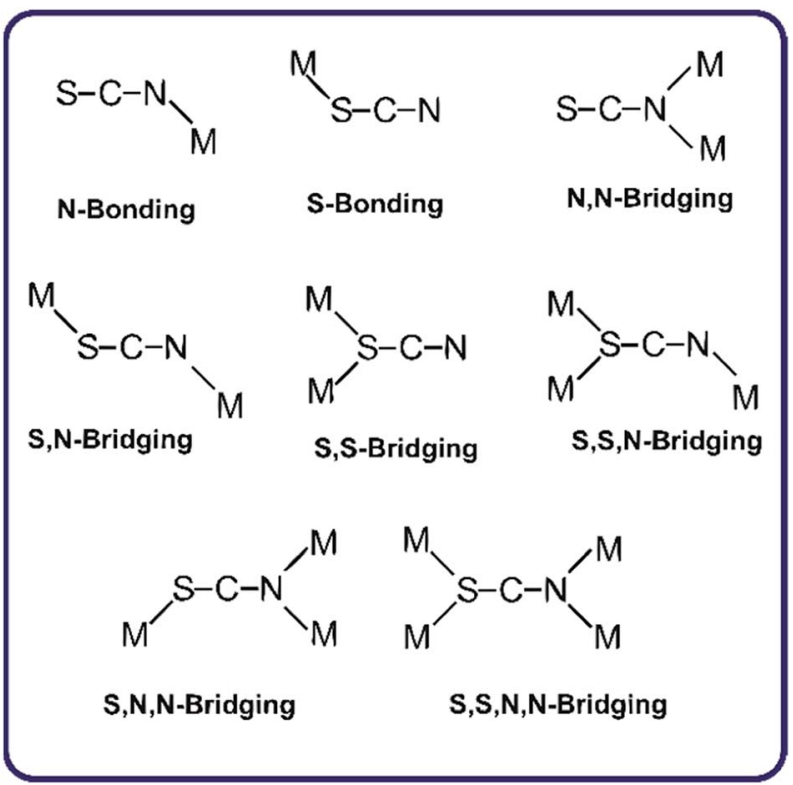

Scheme 1 Possible coordination modes of thiocyanate.

complexes, and that is why this work is of particular interest. The role and importance of $\mathrm{C}-\mathrm{H} \cdots \pi$ interactions has been extensively observed in diverse organic/bioorganic systems, ${ }^{10}$ receiving a special attention in supra-molecular chemistry and crystal engineering. ${ }^{11}$ On the other hand, it is well-known that $\mathrm{C}-\mathrm{H} \cdots \pi$ interaction is a type of hydrogen bond characterized by a shortening of the $\mathrm{C}-\mathrm{H}$ bond and a corresponding blue shift of the $\mathrm{C}-\mathrm{H}$ stretching frequency, when compared to conventional hydrogen bonding. ${ }^{12}$ In the studied complexes, the $\mathrm{C}-\mathrm{H} \cdots \pi$ contacts are afforded through the methyl and aromatic $\mathrm{C}-\mathrm{H}$ groups, which are capable to interact with the imidazole ring leading a shift of the $\mathrm{C}-\mathrm{H}$ stretching mode corresponding to the imidazole ring observed in the IR spectra with respect to the free ligand. The steric and electronic effects of the ligands (methylimidazole) are found to be capable to modify the chain structure. With mono-dentate ligands having the capacity to form additional hydrogen bonding interactions, the chain structure has been extended to higher dimensional hydrogen bonded architectures.

As a part of our continued interest in $\mathrm{Zn}$ (II) and $\mathrm{Cd}(\mathrm{II})$ complexes containing imidazole ligands, we report here the synthesis, spectroscopic studies and crystal structures of two $\mathrm{Zn}$ (II) and two $\mathrm{Cd}(\mathrm{II})$ thiocyanate-bonded complexes with methylimidazole ligands. A detailed analysis of the intermolecular interactions in these complexes was performed by the Hirshfeld surface analysis. Hirshfeld surface (HS) based tools, such as $d_{\text {norm }}$ and shape index surface properties ${ }^{13,14}$, have been used for exploration of the packing modes and visualization of interactions. Full 2D-fingerprint plots have been derived from HSs to calculate the relative percentage of each type of interaction. ${ }^{15,16}$ The intermolecular contacts were further assessed by using the enrichment ratio parameter, ${ }^{17}$ which is a relatively new descriptor, based on Hirshfeld surface analysis, to quantify the likelihood of occurrence of intermolecular contacts in crystals. This magnitude has been recently computed for cadmium complexes. ${ }^{18}$

\section{Experimental}

Commercially available 1-methylimidazole, 2-methylimidazole, $\mathrm{ZnSO}_{4} \cdot 7 \mathrm{H}_{2} \mathrm{O}$, KSCN and $\mathrm{CdBr}_{2}$ were used without further purification.

\subsection{Synthesis of metal complexes 1-4}

2.1.1. [ $\mathrm{Zn}(1-\mathrm{MeIm})_{2}(\mathrm{SCN})_{2}$ ] (1). An aqueous solution of $\mathrm{ZnSO}_{4} \cdot 7 \mathrm{H}_{2} \mathrm{O}(1 \mathrm{mmol})$ was added to an aqueous solution of 1methylimidazole (1-MeIm - $2 \mathrm{mmol})$ and KSCN $(2 \mathrm{mmol})$. The solution was stirred for $1 \mathrm{~h}$ and the resultant colorless solution was left for $24 \mathrm{~h}$ when colorless crystals adequate for X-ray structural determination were obtained. Yield: $75 \%$. Anal. calcd for $\mathrm{C}_{10} \mathrm{H}_{12} \mathrm{~N}_{6} \mathrm{~S}_{2} \mathrm{Zn}$ : C, 34.74; H, 3.47; N, 24.32\%. Found: C, $34.82 ; \mathrm{H}, 3.42$; N, 24.30\%.

2.1.2. $\left[\mathrm{Zn}(2-\mathrm{MeIm})_{2}(\mathrm{SCN})_{2}\right]$ (2). This compound was synthesized by following a similar procedure to the one used for (1) using 2-methylimidazole (2-MeIm), instead of 1-MeIm. Single crystals suitable for structural X-ray diffraction were obtained from the solution after a few days. Yield: $60 \%$. Anal. calcd for $\mathrm{C}_{10} \mathrm{H}_{12} \mathrm{~N}_{6} \mathrm{~S}_{2} \mathrm{Zn}$ : C, $34.74 ; \mathrm{H}, 3.47 ; \mathrm{N}, 24.32 \%$. Found: $\mathrm{C}, 34.80$; $\mathrm{H}, 3.45 ; \mathrm{N}, 24.35 \%$.

2.1.3. [Cd(1-MeIm $\left.)_{4}(\mathrm{SCN})_{2}\right]$ (3). The synthetic procedure was the same as that adopted for (1) but using $\mathrm{CdBr}_{2}(1 \mathrm{mmol})$ as a metal source, instead of $\mathrm{ZnSO}_{4} \cdot 7 \mathrm{H}_{2} \mathrm{O}$. The white precipitate formed was separated by filtration and single crystals suitable for X-ray analysis were obtained by dissolution of the solid in ethanol. Yield: $80 \%$. Anal. calcd for $\mathrm{C}_{18} \mathrm{H}_{24} \mathrm{~N}_{10} \mathrm{~S}_{2} \mathrm{Cd}$ : C, 38.82; H, 4.31 ; N, 25.16\%. Found: C, 38.90; H, 4.36; N, 25.10\%.

2.1.4. $\left[\mathrm{Cd}(2-\mathrm{MeIm})_{2}(\mathrm{SCN})_{2}\right]_{n}(4)$. An aqueous solution of $\mathrm{CdBr}_{2}(1 \mathrm{mmol})$ was added drop-wise under constant stirring to an aqueous solution of 2-MeIm, $(2 \mathrm{mmol})$ and $\mathrm{KSCN}(2 \mathrm{mmol})$. After keeping the stirring during $2 \mathrm{~h}$, the resulting mixture was filtered and the filtrate left for two week until colorless single crystals were obtained. Yield: $50 \%$. Anal. calcd for $\mathrm{C}_{10} \mathrm{H}_{12} \mathrm{~N}_{6} \mathrm{~S}_{2} \mathrm{Cd}: \mathrm{C}, 30.58 ; \mathrm{H}, 3.06 ; \mathrm{N}, 21.41 \%$. Found: $\mathrm{C}, 30.75 ; \mathrm{H}$, $3.08 ; \mathrm{N}, 21.48 \%$.

\subsection{Instrumentation}

Elemental analyses (carbon, hydrogen and nitrogen) were performed using a CarloErba elemental analyzer. The Infrared (IR) absorption spectra were measured at room temperature in $\mathrm{KBr}$ pellets, with a resolution of $2 \mathrm{~cm}^{-1}$ on a FTIR Perkin Elmer GX1 in the frequency range $4000-400 \mathrm{~cm}^{-1}$. The Raman spectra of the solids were recorded in a $3500-50 \mathrm{~cm}^{-1}$ interval with a Thermo scientific DXR Raman microscope. The Raman dispersion data were collected using a diode-pump, solid state laser of $780 \mathrm{~nm}$ (at $5 \mathrm{~cm}^{-1}$ spectral resolution), a con-focal aperture of $25 \mu \mathrm{m}$ pinhole and a $10 \times$ objective lens. Thermogravimetric (TG) and differential thermal analysis (DTA) were performed with a Shimadzu DTG-50 thermo-balance in the 25$800{ }^{\circ} \mathrm{C}$ range at a heating rate of $5^{\circ} \mathrm{min}^{-1}$ under air flow. The electronic absorption spectra of 1-MeIm, 2-MeIm and 1-4 
complexes were recorded on a Beckman/DU 7500 spectrophotometer in the $200-800 \mathrm{~nm}$ spectral range on samples dissolved in acetonitrile at $1 \times 10^{-3} \mathrm{M}$ concentration. Fluorescence spectra of the ligands and complexes dissolved in acetonitrile at a concentration of $1 \times 10^{-4} \mathrm{M}$ were recorded with a Deltaflex Horiba spectrofluorometer using a diode laser $(\lambda=267 \mathrm{~nm})$ for the excitation of the samples.

\subsection{X-ray structure determination}

The measurements were performed on an Oxford Xcalibur, Eos, Gemini CCD diffractometer with graphite-monochromated $\operatorname{MoK} \alpha(\lambda=0.7107 \AA)$ radiation. X-ray diffraction intensities were collected ( $\omega$ scans with $\theta$ and $\kappa$-offsets), integrated and scaled with CrysAlisPro suite of programs. ${ }^{19}$ The unit cell parameters were obtained by least-squares refinement (based on the angular settings for all collected reflections with intensities larger than seven times the standard deviation of measurement errors) using CrysAlisPro. Data were corrected empirically for absorption employing the multi-scan method implemented in CrysAlisPro. The structures were solved by intrinsic phasing with SHELXT of the SHELX suit of programs. ${ }^{20}$ Molecular models were refined by full-matrix least-squares procedure with SHELXL of the same package. The hydrogen atoms were positioned on stereo-chemical bases and refined with the riding model. The methyl $\mathrm{H}$-atoms were refined as rigid groups allowed to rotate around their corresponding $\mathrm{C}-\mathrm{C}$ or $\mathrm{N}-\mathrm{C}$ bond such as to maximize the sum of the observed residual electron density at their calculated positions. Crystal data, data collection procedure, and refinement results for all four complexes are summarized in Table 1.

\subsection{Hirshfeld surface calculations}

Hirshfeld surfaces and the associated 2D-fingerprint plots ${ }^{24-27}$ are generated using CrystalExplorer3.0 software. ${ }^{28}$ The normalized contact distance $\left(d_{\text {norm }}\right)$ enables the identification of the regions of particular importance to the intermolecular interactions, being $d_{\text {norm }}$ a symmetric function of distances to the surface from nuclei inside and outside the Hirshfeld surface $\left(d_{\mathrm{i}}\right.$ and $d_{\mathrm{e}}$, respectively), relative to their respective van der Waals radii. Hirshfeld surfaces for the title structures were also mapped with the shape index property. The 2D-fingerprint plot provides decomposition of Hirshfeld surfaces into relative contribution of different intermolecular interactions present in the crystal structures. ${ }^{29}$ A color scale of red (shorter than vdW separation)-white (equal to vdW separation)-blue (longer than vdW separation) is used to visualize the intermolecular contacts in the $d_{\text {norm }}$ plot. The $3 \mathrm{D} d_{\text {norm }}$ surfaces are mapped over a fixed color scale of -0.085 (red) to 1.090 (blue), and shape index mapped in the color range of -1.0 a.u. (concave) to 1.0 a.u. (convex) Å.

\section{Results and discussion}

\subsection{Description of the crystal structures}

3.1.1. $\quad\left[\mathrm{Zn}(1-\mathrm{MeIm})_{2}(\mathrm{SCN})_{2}\right], 1$-MeIm $=1$-methylimidazole (1). Fig. 1a shows the coordination sphere of the complex $\mathbf{1}$, and

Table 1 Crystal data and structure refinement for complexes 1-4

\begin{tabular}{|c|c|c|c|c|}
\hline & Complex 1 & Complex 2 & Complex 3 & Complex 4 \\
\hline Empirical formula & $\mathrm{C}_{10} \mathrm{H}_{12} \mathrm{~N}_{6} \mathrm{~S}_{2} \mathrm{Zn}$ & $\mathrm{C}_{10} \mathrm{H}_{12} \mathrm{~N}_{6} \mathrm{~S}_{2} \mathrm{Zn}$ & $\mathrm{C}_{18} \mathrm{H}_{24} \mathrm{CdN}_{10} \mathrm{~S}_{2}$ & $\mathrm{C}_{10} \mathrm{H}_{12} \mathrm{CdN}_{6} \mathrm{~S}_{2}$ \\
\hline Formula weight & 345.75 & 345.75 & 556.99 & 392.78 \\
\hline Temperature/K & $297(2)$ & $293(2)$ & $293(2)$ & $293(2)$ \\
\hline Crystal system & Monoclinic & Orthorhombic & Triclinic & Orthorhombic \\
\hline Space group & $P 2_{1} / c$ & Pnma & $P \overline{1}$ & $C m c 2_{1}$ \\
\hline \multirow[t]{6}{*}{ Unit cell dimensions } & $a=11.9876(6) \AA$ & $a=8.4322(3) \AA$ & $a=8.1914(3) \AA$ & $a=13.9249(4) \AA$ \\
\hline & $b=11.6755(4) \AA$ & $b=12.5613(5) \AA$ & $b=8.7859(6) \AA$ & $b=14.7811(4) \AA$ \\
\hline & $c=11.8909(5) \AA$ & $c=13.9647(5) \AA$ & $c=9.4685(6) \AA$ & $c=6.9732(2) \AA$ \\
\hline & - & - & $\alpha=90.962(6)^{\circ}$ & - \\
\hline & $\beta=109.447(5)$ & - & $\beta=112.629(5)^{\circ}$ & - \\
\hline & - & - & $\gamma=104.257(5)^{\circ}$ & - \\
\hline Volume $/ \AA^{3}$ & $1569.3(1)$ & $1479.13(10)$ & $604.85(7)$ & $1435.26(7)$ \\
\hline$Z$ & 4 & 4 & 1 & 4 \\
\hline$\rho$ calc. $/ \mathrm{mg} \mathrm{mm} \mathrm{m}^{-3}$ & 1.463 & 1.553 & 1.529 & 1.818 \\
\hline$\mu / \mathrm{mm}^{-1}$ & 1.826 & 1.937 & 1.101 & 1.807 \\
\hline$F(000)$ & 704 & 704 & 282 & 776 \\
\hline Crystal size/mm $\mathrm{mm}^{3}$ & $0.282 \times 0.134 \times 0.098$ & $0.209 \times 0.143 \times 0.048$ & $0.441 \times 0.337 \times 0.138$ & $0.377 \times 0.260 \times 0.211$ \\
\hline$\theta$-range for data collection $\left(^{\circ}\right)$ & 3.43 to 28.82 & 2.92 to 29.04 & 3.16 to 28.63 & 2.93 to 28.95 \\
\hline Index ranges & $-16 \leq h \leq 9$ & $-7 \leq h \leq 11$ & $-9 \leq h \leq 10$ & $-17 \leq h \leq 15$ \\
\hline & $-15 \leq k \leq 13$ & $-16 \leq k \leq 15$ & $-11 \leq k \leq 7$ & $-13 \leq k \leq 19$ \\
\hline & $-15 \leq l \leq 14$ & $-18 \leq l \leq 17$ & $-12 \leq l \leq 11$ & $-9 \leq l \leq 6$ \\
\hline Reflections collected & 7733 & 4502 & 4285 & 2057 \\
\hline Independent reflections & $3397[R(\mathrm{int})=0.0272]$ & $1742[R($ int $)=0.045]$ & $2584[R($ int $)=0.0251]$ & $1166[R(\mathrm{int})=0.0218]$ \\
\hline Data/restraints/parameters & $3397 / 0 / 198$ & $1742 / 0 / 98$ & $2584 / 0 / 144$ & $1166 / 1 / 99$ \\
\hline Goodness-of-fit on $F^{2}$ & 1.006 & 1.063 & 1.063 & 1.032 \\
\hline Final $R$ indexes $[I>2 \sigma(I)]$ & $\begin{array}{l}R 1=0.0393 \\
w R 2=0.0803\end{array}$ & $\begin{array}{l}R 1=0.0386 \\
w R 2=0.0727\end{array}$ & $\begin{array}{l}R 1=0.0256 \\
w R 2=0.0632\end{array}$ & $\begin{array}{l}R 1=0.0199 \\
w R 2=0.0444\end{array}$ \\
\hline Largest diff. peak/hole/e $\AA^{-3}$ & $0.326 /-0.277$ & $0.302 /-0.319$ & $0.248 /-0.632$ & $0.545 /-0.367$ \\
\hline
\end{tabular}




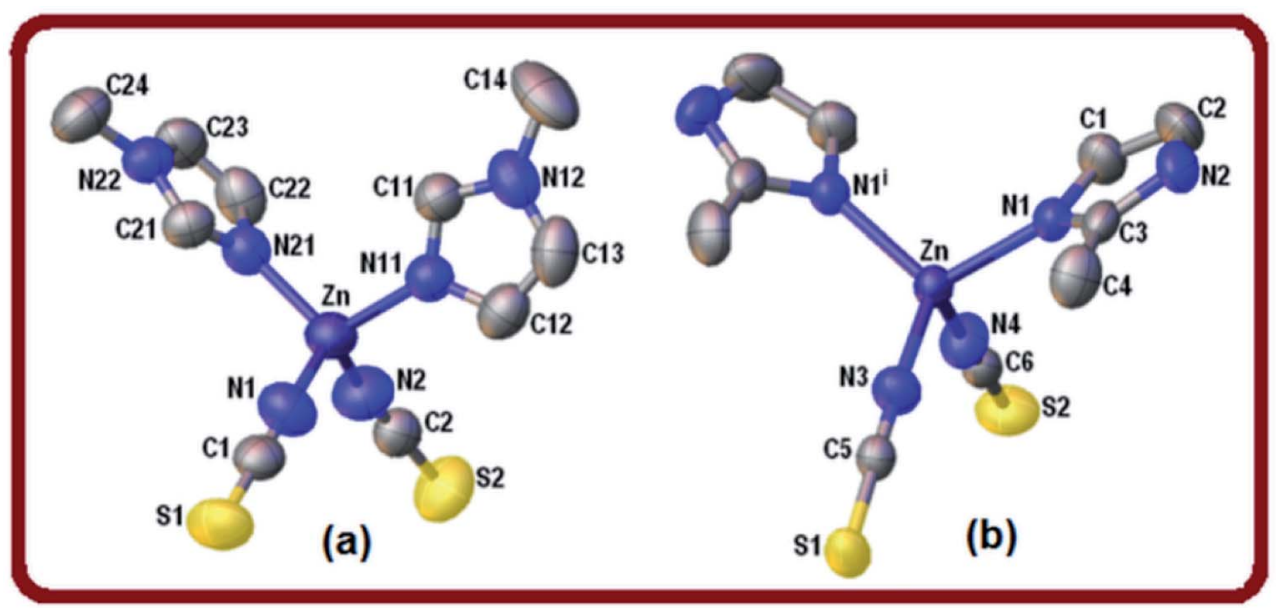

Fig. 1 View of the zinc complexes 1 (a) and 2 (b) showing the labeling of the atoms and their displacement ellipsoids at the $50 \%$ probability level. $\mathrm{H}$-atoms are omitted for clarity. Symmetry operation for 2 (i): $x, 1 / 2-y, z$.

its bond distances and angles around the zinc ion are presented in Table 2. The molecule appears in the lattice as mono-nuclear units with the $\mathrm{Zn}$ (II) ion at a general crystallographic position in a tetrahedral coordination with the nitrogen atoms of two different thiocyanate $\left(\mathrm{SCN}^{-}\right)$[ $\mathrm{Zn}-\mathrm{N}$ bond distances of 1.953(3) and 1.943(3) ̊̊] in a relatively linear Zn-NCS conformation [Zn$\mathrm{N}-\mathrm{CS}$ bond angles of $173.5(3)$ and $\left.163.4(3)^{\circ}\right]$ and to two 1-MeIm molecules through their pyridine-like nitrogen atoms $[\mathrm{Zn}-\mathrm{N}$ bond lengths of 1.994(2) $\AA$ and 1.986(2) $\AA$. L-Zn-L bond angles in the $\mathrm{ZnN}_{4}$ core are in the 107.5(1)-113.3(1) ${ }^{\circ}$ range. A geometry index $\tau_{4}$ has been proposed to describe the geometry of fourcoordinate complexes. ${ }^{30}$ The values of $\tau_{4}$ fall between 1.00 for a perfect tetrahedral geometry and zero for an ideal square planar geometry. ${ }^{31}$ Parameter $\tau_{4}$ calculated for complex 1 is equal to 0.99 which confirms an ideal tetrahedral geometry around the zinc ion. The shortest metal-metal separation is 5.769(1) A. The molecules of complex are packed by weak intermolecular $\mathrm{C}-\mathrm{H} \cdots \mathrm{S}$ hydrogen bonds $\left[d(\mathrm{H} \cdots \mathrm{S})=2.93(3) \AA, \angle(\mathrm{C}-\mathrm{H} \cdots \mathrm{S})=148^{\circ}\right]$ (Table 3 ) forming $R_{2}^{2}$ (14) ring motifs (see Fig. S1, ESI $\dagger$ ).

3.1.2. $\left[\mathrm{Zn}(2-\mathrm{MeIm})_{2}(\mathrm{SCN})_{2}\right], 2$-MeIm $=2$-methylimidazole (2). Fig. $1 \mathrm{~b}$ shows the coordination sphere of the complex 2, and its bond distances and angles around the zinc ion are presented in Table 2. The molecule appears in the lattice as monomeric units, with the $\mathrm{Zn}(\mathrm{II})$ ion sited at a crystallographic mirror plane in a tetrahedral coordination with the nitrogen atoms of two different thiocyanate $\left(\mathrm{SCN}^{-}\right)$ions laying on the plane $[\mathrm{Zn}-\mathrm{N}$ bond distances of 1.954(4) and 1.988(4) $\mathrm{A}]$ in a relatively linear $\mathrm{Zn}$-NCS conformation [Zn-N-CS bond angles of 177.3(4) and $\left.174.0(4)^{\circ}\right]$ and to two mirror-related 2-MeIm molecules through their pyridine-like nitrogen atoms $[d(\mathrm{Zn}-\mathrm{N})=1.992(2) \AA]$. $\mathrm{L}-\mathrm{Zn}-$ $\mathrm{L}$ bond angles in the $\mathrm{ZnN}_{4}$ core are in the 104.3(1)-113.8(1) ${ }^{\circ}$ range.

Parameter $\tau_{4}$ calculated for complex 2 is equal to 0.96 which confirms almost ideal tetrahedral geometry around the zinc ion. The shortest metal-metal separation is 6.314(1) $\AA$. The crystal packing of complex 2 is directed by weak ${ }^{32}$ intermolecular $\mathrm{N}-\mathrm{H} \cdots \mathrm{S}$ hydrogen bonds $[d(\mathrm{H} \cdots \mathrm{S})=2.676(1) \AA, \angle(\mathrm{N}-\mathrm{H} \cdots \mathrm{S})=$ $154^{\circ}$ ] (Table 3) forming $R_{4}^{3}$ (26) ring motifs (see Fig. S2, ESI $\dagger$ ).

Two different $\pi$-stacking contacts also contribute to the crystal stability of 2 . On one hand, a weak $\mathrm{C}-\mathrm{H} \cdots \pi$ interaction involves the methyl $\mathrm{C} 4-\mathrm{H} 4 \mathrm{C}$ group donor and the imidazole ring [ $\mathrm{Cg} 1$ centroid, $\mathrm{H} \cdots \mathrm{Cg} 1=3.00 \AA]$ (Table 4). By the other hand, an unusual lone-pair (l.p.) $\cdots \pi$ interaction involves the thiocyanate sulfur S2 lone pair(s) and the aromatic ring. This interesting $\mathrm{C}=\mathrm{S}(\mathrm{l} . \mathrm{p}.) \cdots \pi$ interaction is characterized by a short S2 $\cdots \mathrm{Cg} 1$ distance of 3.831(1) $\AA$, and the angular distribution

Table 2 Selected bond lengths and angles around the metals in complexes 1-4 $\left(\AA,^{\circ}\right)$

\begin{tabular}{|c|c|c|c|c|c|c|c|}
\hline \multicolumn{2}{|l|}{ Compound 1} & \multicolumn{2}{|l|}{ Compound 2} & \multicolumn{2}{|l|}{ Compound 3} & \multicolumn{2}{|l|}{ Compound 4} \\
\hline $\mathrm{Zn}-\mathrm{N} 1$ & $1.953(3)$ & $\mathrm{Zn}-\mathrm{N} 1$ & $1.992(2)$ & $\mathrm{Cd}-\mathrm{N} 1$ & $2.353(2)$ & $\mathrm{Cd}-\mathrm{S} 1$ & $2.605(2)$ \\
\hline Zn-N2 & $1.943(3)$ & $\mathrm{Zn}-\mathrm{N} 3$ & $1.954(4)$ & Cd-N11 & $2.358(2)$ & Cd-N1 & $2.377(4)$ \\
\hline Zn-N11 & $1.988(3)$ & $\mathrm{Zn}-\mathrm{N} 4$ & $1.988(3)$ & $\mathrm{Cd}-\mathrm{N} 21$ & $2.334(2)$ & $\mathrm{Cd}-\mathrm{N} 2$ & $2.348(5)$ \\
\hline & & & & & & $\mathrm{Cd}-\mathrm{N} 3$ & $2.241(3)$ \\
\hline N11-Zn-N21 & 107.5(1) & $\mathrm{N} 1-\mathrm{Zn}-\mathrm{N} 1^{a}$ & $110.8(1)$ & N1-Cd-N11 & $88.1(1)$ & N1-Cd-N2 & $166.3(2)$ \\
\hline N1-Zn-N11 & $108.2(1)$ & N1-Zn-N3 & $113.8(1)$ & N1-Cd-N21 & $91.4(1)$ & $\mathrm{N} 3-\mathrm{Cd}-\mathrm{N} 3^{c}$ & $146.2(2)$ \\
\hline N1-Zn-N21 & 108.1(1) & $\mathrm{N} 1-\mathrm{Zn}-\mathrm{N} 4$ & $104.3(1)$ & $\mathrm{N} 1-\mathrm{Cd}-\mathrm{N} 1^{b}$ & $180.0(1)$ & N3-Cd-S1 & $106.8(1)$ \\
\hline Zn-N1-C1 & $173.6(3)$ & $\mathrm{Zn}-\mathrm{N} 3-\mathrm{C} 5$ & $174.0(4)$ & $\mathrm{Cd}-\mathrm{N} 1-\mathrm{C} 1$ & $144.7(2)$ & Cd-N1-C1 & $157.0(5)$ \\
\hline $\mathrm{Zn}-\mathrm{N} 2-\mathrm{C} 2$ & 163.4(3) & Zn-N4-C6 & $177.3(4)$ & & & $\mathrm{Cd}-\mathrm{N} 2-\mathrm{C} 2$ & $156.3(5)$ \\
\hline
\end{tabular}

${ }^{a}$ Symmetry codes: $x,-y+1 / 2, z$ for $2 .{ }^{b}$ Symmetry codes: $-x+1,-y,-z+1$ for $3{ }^{c}$ Symmetry codes: $-x+1, y, z$ for 4 . 
Table 3 Geometry of intermolecular hydrogen bonds for complexes 1-4 $\left(\AA,{ }^{\circ}\right)$

\begin{tabular}{|c|c|c|c|c|}
\hline $\mathrm{D}-\mathrm{H} \cdots \mathrm{A}$ & $d(\mathrm{D}-\mathrm{H})$ & $d(\mathrm{H} \cdots \mathrm{A})$ & $d(\mathrm{D} \cdots \mathrm{A})$ & $\angle(\mathrm{D}-\mathrm{H} \cdots \mathrm{A})$ \\
\hline \multicolumn{5}{|l|}{ Compound 1} \\
\hline $\mathrm{C} 11-\mathrm{H} 11 \cdots \mathrm{S} 1^{a}$ & $0.93(4)$ & $2.93(3)$ & $3.749(4)$ & 148 \\
\hline \multicolumn{5}{|l|}{ Compound 2} \\
\hline $\mathrm{N} 2-\mathrm{H} 2 \mathrm{~A} \cdots \mathrm{S} 1^{b}$ & $0.860(3)$ & $2.676(1)$ & $3.469(3)$ & 154 \\
\hline \multicolumn{5}{|l|}{ Compound 3} \\
\hline $\mathrm{C} 24-\mathrm{H} 24 \mathrm{C} \cdots \mathrm{S} 1^{c}$ & $0.960(3)$ & $2.823(1)$ & $3.740(3)$ & 160 \\
\hline $\mathrm{C} 13-\mathrm{H} 13 \cdots \mathrm{S} 1^{d}$ & $0.960(3)$ & $3.004(1)$ & $3.878(2)$ & 157 \\
\hline \multicolumn{5}{|l|}{ Compound 4} \\
\hline $\mathrm{N} 4-\mathrm{H} 4 \mathrm{~A} \cdots \mathrm{S} 2^{e}$ & $0.860(3)$ & $2.583(1)$ & $3.404(3)$ & 160 \\
\hline $\mathrm{C} 5-\mathrm{H} 5 \cdots \mathrm{S} 1^{f}$ & $0.930(4)$ & $2.936(1)$ & $3.731(4)$ & 144 \\
\hline
\end{tabular}

${ }^{a}$ Symmetry operations: $1-x, 1-y, 1-z$ for $1 .{ }^{b}$ Symmetry operations: $3 / 2-x, 1-y, 1 / 2+z$ for $2 .^{c}$ Symmetry operations: $1-x, 1-y, 1-z$ for $3{ }^{d}$ Symmetry operations: $x, y,-1+z$ for $3{ }^{e}$ Symmetry operations: $1 / 2-$ $x, 1 / 2-y, 1 / 2+z$ for $4 .{ }^{f}$ Symmetry operations: $1-x, 1-y,-1 / 2+z$ for 4.

[deviation of the angle $\alpha\left(\alpha\right.$ is the angle $\mathrm{C}=\mathrm{S} \cdots \mathrm{Cg}$ ) from $120^{\circ}$ ] of $18^{\circ}$ is in the range of the mean value of $30.6^{\circ}$ reported for $\mathrm{C}=$ $\mathrm{O}($ l.p. $) \cdots \pi$ interactions. ${ }^{33,34}$ In addition, these contacts are significant through the dihedral angle $\omega=60.6^{\circ}$ between the $\mathrm{N} 4-\mathrm{C} 6=\mathrm{S} 2$ moiety and imidazole ring mean planes indicating that the thiocyanate group takes an angular approach towards the ring $\left(25 \leq \omega \leq 64^{\circ}\right){ }^{33}$

3.1.3. [ $\left.\mathrm{Cd}(1-\mathrm{MeIm})_{4}(\mathrm{SCN})_{2}\right]$ (3). Fig. 2a shows the coordination sphere of complex $\mathbf{3}$, and its bond distances and angles around cadmium ion are detailed in Table 2 . The $\mathrm{Cd}(\mathrm{II})$ ion is located at a crystallographic inversion centre. It is in a quite regular octahedral environment, equatorially coordinated to two independent 1-MeIm ligands through their $\mathrm{N}$-atoms [Cd-N bond distances of 2.358(2) and 2.334(2) $\mathrm{A}]$ and to the nitrogen atoms of two inversion-related thiocyanate ions $[d(\mathrm{Cd}-\mathrm{N})=$ $2.353(2) \AA]$ in an appreciable bent Cd-NCS conformation $\left[\angle(\mathrm{Cd}-\mathrm{N}-\mathrm{CS})=144.7(2)^{\circ}\right]$. Trans $\mathrm{L}-\mathrm{Cd}-\mathrm{L}$ bond angles in the $\mathrm{CdN}_{6}$ core are in the range from 88.1(1) to $91.4(1)^{\circ}$. The shortest metal-metal separation is 8.786(1) $\AA$. The supra-molecular self- assembly of complex 3 is conducted by weak $\mathrm{C}-\mathrm{H} \cdots \mathrm{S}$ hydrogen bonds (Table 3, Fig. S3, ESI $\dagger$ ), and three kinds of $\mathrm{C}-\mathrm{H} \cdots \pi$ interactions (Table 4 ) between methylimidazole moieties, which are referred to as point-to-face or T-shaped arrangements. ${ }^{35}$

3.1.4. $\left[\mathrm{Cd}(2-\mathrm{MeIm})_{2}(\mathrm{SCN})_{2}\right]_{n}(4)$. Fig. $2 \mathrm{~b}$ shows a drawing of the coordination polymer of complex $\mathbf{4}$, and the corresponding bond distances and angles around the metal (Table 2) are in agreement with those found in similar polymeric $\mathrm{Cd}(\mathrm{II})$ complexes mediated by N-bonded thiocyanate. ${ }^{8}$ The $\mathrm{Cd}(\mathrm{II})$ ion is sited on a crystallographic mirror plane perpendicular to the $a$ axis $(1 / 2, y, z)$ in a square basis pyramidal environment, $\operatorname{CdN}_{4} \mathrm{~S}$, trans-coordinated at the pyramid basis to the $\mathrm{N}$-atoms of two SCN groups [Cd-N distances of 2.377(4) and 2.348(5) $\mathrm{A}]$ laying on the mirror plane in a slightly bent Cd-NCS conformation $\left[\mathrm{Cd}-\mathrm{N}-\mathrm{CS}\right.$ angles of $157.0(5)$ and $\left.156.3(5)^{\circ}\right]$ and to the nitrogen atoms $[d(\mathrm{Cd}-\mathrm{N})=2.241(3) \AA]$ of two mirror-related 2-MeIm ligands. The five-fold coordination is completed at the pyramid apex by the sulfur atom $[d(\mathrm{Cd}-\mathrm{S})=2.605(1) \AA]$ of a SCN ligand belonging to a two-fold screw axis-related neighboring complex. The index of the degree of trigonality $\tau_{5}=0.33$ indicates that the $\mathrm{Cd}(\mathrm{II})$ ion shows a distorted square-pyramid environment, i.e., within the structural continuum between trigonal bipyramidal and square or rectangular pyramidal. ${ }^{36}$ For an ideal tetragonal geometry $\tau_{5}$ is equal to zero, while it becomes unity for perfect trigonal-bipyramidal geometry.

In the $\mathrm{CdN}_{4} \mathrm{~S}$ coordination core the metal departs from the mean plane of nitrogen atoms at the basis in 0.466(3) A towards the apical sulfur atom. The coordination bonding gives rise to a zig-zag chain arrangement of $\mathrm{Cd}(2-\mathrm{MeIm})_{2}(\mathrm{SCN})_{2}$ monomers that extends along the crystal $c$-axis (Fig. 2b). Alternatively, the chain can be described as an helix wound around the crystallographic two-fold screw axis with a pitch equal to the unit cell length $c$ and having two symmetry related $\mathrm{Cd}(2-\mathrm{MeIm})_{2}(\mathrm{SCN})_{2}$ monomers per turn. The bent and zigzagged conformations in this complex explain the observed very short inter-metallic distance of 5.673(1) $\AA$ in the polymeric chain when compared with those for similar compounds. ${ }^{8}$ Hydrogen bond interactions in coordination polymers play an important role in the crystal packing. ${ }^{37}$ Neighboring chains in the lattice are linked to each other through a weak $\mathrm{N}-\mathrm{H} \cdots \mathrm{S}[d(\mathrm{H} \cdots \mathrm{S})=2.583(1) \AA, \angle(\mathrm{N}-$

Table 4 Geometry of $\mathrm{C}-\mathrm{H} \cdots \pi$ interactions $^{a}$ for complexes $2-4\left(\AA,^{\circ}\right)$

\begin{tabular}{|c|c|c|c|c|c|c|}
\hline $\mathrm{C}-\mathrm{H} \cdots \mathrm{Cg}(j)^{b}$ & Symmetry & $\mathrm{H} \cdots \mathrm{Cg}$ & H-perp ${ }^{c}$ & $\gamma^{d}$ & $\mathrm{C}-\mathrm{H} \cdots \mathrm{Cg}$ & $\mathrm{H} \cdots \mathrm{C}^{e}$ \\
\hline \multicolumn{7}{|l|}{ Compound 2} \\
\hline $\mathrm{C} 4-\mathrm{H} 4 \mathrm{C} \cdots \mathrm{Cg}(1)$ & $1-x, 1-y, 1-z$ & 3.00 & 2.82 & 19.79 & 146 & $2.832(3)$ \\
\hline \multicolumn{7}{|l|}{ Compound 3} \\
\hline $\mathrm{C} 14-\mathrm{H} 14 \mathrm{~B} \cdots \mathrm{Cg}(1)$ & $-x,-y,-z$ & 2.86 & 2.79 & 13.26 & 135 & $2.992(2)$ \\
\hline $\mathrm{C} 22-\mathrm{H} 22 \cdots \mathrm{Cg}(1)$ & $1-x, 1-y, 1-z$ & 2.58 & 2.58 & 3.99 & 170 & $2.852(2)$ \\
\hline $\mathrm{C} 24-\mathrm{H} 24 \mathrm{~B} \cdots \mathrm{Cg}(2)$ & $2-x, 1-y, 1-z$ & 2.86 & 2.78 & 13.60 & 123 & $2.815(2)$ \\
\hline \multicolumn{7}{|l|}{ Compound 4} \\
\hline C6-H6C $\cdots \mathrm{Cg}(1)$ & $x, 1-y, 1 / 2+z$ & 2.91 & 2.87 & 9.32 & 113 & $3.052(5)$ \\
\hline
\end{tabular}

${ }^{a}\left(\mathrm{H} \cdots \mathrm{Cg}<3.0 \AA, \gamma<30.0^{\circ}\right) .{ }^{b}$ Centroid of aromatic rings. ${ }^{c}$ Perpendicular distance of $\mathrm{H}$ to ring plane $J .{ }^{d}$ Angle between the Cg-H vector and ring $J$ normal. ${ }^{e}$ Distance between $\mathrm{H}$-atom and the nearest carbon atom in the aromatic ring. 


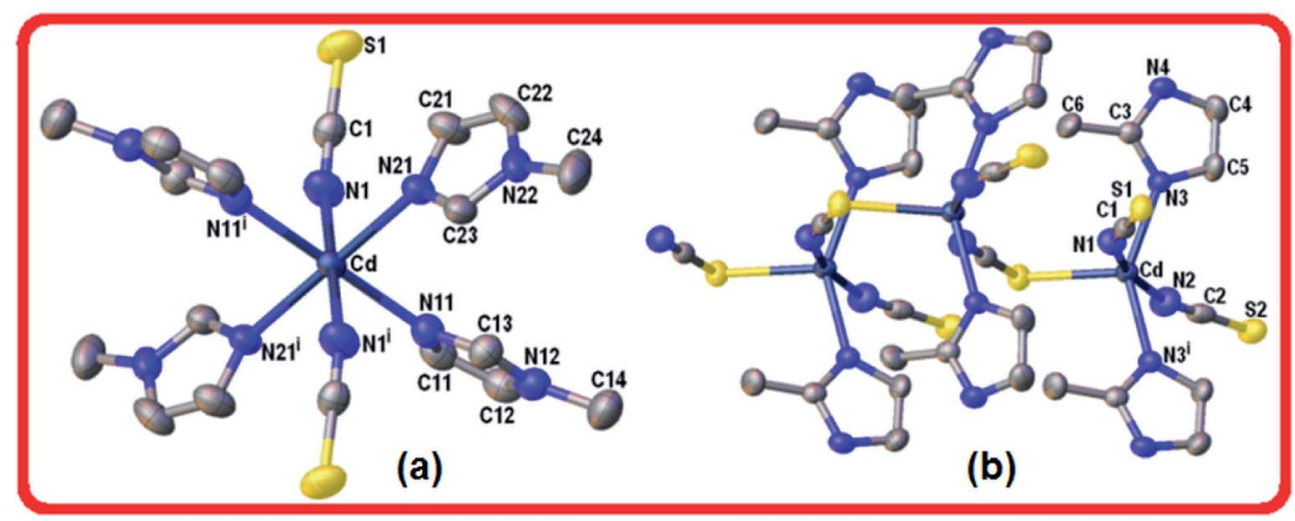

Fig. 2 (a) View of the cadmium complex 3, and (b) view of the zig-zag chain for the polymeric complex 4 showing one $\mu$-SCN anion linking two $\mathrm{CdL}_{2}$ units $(\mathrm{L}=2$-methylimidazole). Displacement ellipsoids are shown at the $50 \%$ probability level. $\mathrm{H}$-atoms are omitted for clarity. Symmetry operations: for 3 (i) $1-x,-y, 1-z$; for 4 (i) $1-x, y, z$.

$\left.\mathrm{H} \cdots \mathrm{S})=160^{\circ}\right]$ and longer $\mathrm{C}-\mathrm{H} \cdots \mathrm{S}$ hydrogen bonds $[d(\mathrm{H} \cdots \mathrm{S})=$ 2.936(1) $\left.\AA, \angle(\mathrm{N}-\mathrm{H} \cdots \mathrm{S})=144^{\circ}\right]$ leading to the formation of a 3D network (Table 3, Fig. S4, ESI $\dagger$ ). The crystal packing appears to be also controlled by weak $\mathrm{C}-\mathrm{H} \cdots \pi$ interactions involving the methyl C6-H6C donor (Table 4).

\subsection{Hirshfeld surface analysis}

Hirshfeld surface analysis have been carried out to get a better comprehension on the nature of packing motifs and the contribution of the main intermolecular interactions directing the molecular architecture in crystalline complexes 1-4. Fig. 3 shows Hirshfeld surfaces (HSs) mapped over the $d_{\text {norm }}$ property in two orientations (columns 1 and 2), and the corresponding full two-dimensional fingerprint plots (FPs) are displayed in column 3. The surfaces are shown as transparent to allow visualization of the molecules. Contacts with distances equal to the sum of the van der Waals radii are represented as white regions and the contacts with distances shorter than and longer than van der Waals radii are shown as red and blue colors, respectively. The relative contributions to the Hirshfeld surface area due to the main intermolecular interactions are shown as histogram in Fig. 4.

The large red regions labeled 1 in Fig. 3 represent $\mathrm{H} \cdots \mathrm{S} / \mathrm{S} \cdots \mathrm{H}$ contacts, which are relevant in the $d_{\text {norm }}$ maps for all the four compounds. In the zinc complexes ( $\mathbf{1}$ and $\mathbf{2})$, these contacts are attributed to $\mathrm{C} 11-\mathrm{H} 11 \cdots \mathrm{S} 1$ and $\mathrm{N} 2-\mathrm{H} 2 \mathrm{~A} \cdots \mathrm{S} 1$ hydrogen bonds (Fig. 3), respectively, which can also be seen in the FPs as a pair of symmetrical spikes at $\left(d_{\mathrm{e}}+d_{\mathrm{i}}\right) \cong 2.8 \AA$ for the former, and $\left(d_{\mathrm{e}}\right.$ $\left.+d_{\mathrm{i}}\right) \cong 2.6 \AA$ for the later interaction, in agreement with the expected higher strength for the N2-H2A $\cdots \mathrm{S} 1$ hydrogen bond. The $\mathrm{H} \cdots \mathrm{S} / \mathrm{S} \cdots \mathrm{H}$ contacts are dominant for complexes $\mathbf{1}$ and $\mathbf{2}$, with highest contributions of $33.7 \%$ and $30.1 \%$, respectively, of the total Hirshfeld surface area (see Fig. 4).

Four small red spots labeled 2 for compounds 1 and 2 (Fig. 3, column 2) represent $\mathrm{H} \cdots \mathrm{C} / \mathrm{C} \cdots \mathrm{H}$ contacts with large and similar area fractions of 20.7 and $22.2 \%$, respectively. However, unlike of $\mathbf{1}$, where no significant $\mathrm{C}-\mathrm{H} \cdots \pi$ interactions are observed, the $\mathrm{H} \cdots \mathrm{C} / \mathrm{C} \cdots \mathrm{H}$ contacts in 2 appear in a characteristic way for $\mathrm{C}-$ $\mathrm{H} \cdots \pi$ interactions, i.e. in the form of pronounced "wings" on the sides of the FP with the shortest $\left(d_{\mathrm{i}}+d_{\mathrm{e}}\right) \cong 2.7-2.8 \AA$, and comprising a $22.2 \%$ of the total Hirshfeld surface area. ${ }^{38}$ Two upper spots are associated to the acceptor region of the FP (lower right) corresponding to a $12.6 \%$ contribution from $\mathrm{C} \cdots \mathrm{H}$ contacts (C inside the surface), while the other two spots are related to the donor region in the FP (upper left) with a lower contribution of $9.6 \%$ from $\mathrm{H} \cdots \mathrm{C}$ contacts ( $\mathrm{H}$ inside the surface). A view of shape index surface (Fig. 5a) confirms the existence of point-to-face $\mathrm{C}-\mathrm{H} \cdots \pi$ interactions (Table 4 ) showing a large red depression above the electron system and a blue region surrounding the $\mathrm{C}-\mathrm{H}$ donor, both the regions highlighted by black circles. Finally, the $\mathrm{H} \cdots \mathrm{H}$ interactions labeled 5 in the middle of scattered points in FP, are showed as two symmetrical broad regions with minimum $\left(d_{\mathrm{e}}+d_{\mathrm{i}}\right)$ contact distance around $2.6 \AA$ (longer than the sum of van der Waals radii), comprising a $24.5 \%$ contribution to the Hirshfeld surface area.

In compound 3, the tiny red regions labeled 1 in the $d_{\text {norm }}$ surfaces (Fig. 3) are attributed to $\mathrm{C} 24-\mathrm{H} 24 \mathrm{C} \cdots \mathrm{S} 1$ hydrogen bonds (Fig. 2a), and represented as a pair of short spikes highlighted in red at $\left(d_{\mathrm{e}}+d_{\mathrm{i}}\right) \cong 2.6 \AA$ in $\mathrm{FP}$, with a high $21.6 \%$ contribution. Like in structure 2 , the small red spots labeled 2 indicate weak $\mathrm{H} \cdots \mathrm{C} / \mathrm{C} \cdots \mathrm{H}$ contacts corresponding to point-toface $\mathrm{C}-\mathrm{H} \cdots \pi$ interactions (Table 4 ), which also appear as two broad spikes at $\left(d_{\mathrm{e}}+d_{\mathrm{i}}\right) \cong 2.7 \AA$ in the FP with $22.8 \%$ contribution to the Hirshfeld surface area, and in shape index surface (Fig. 5b). The $\mathrm{H} \cdots \mathrm{H}$ contacts (labeled 5) are visible showing a single broad peak in the middle region of FP, and represent the dominant interactions $(41.9 \%$ contribution $)$ in this $\mathrm{Cd}$ complex.

In compound 4 , the $\mathrm{H} \cdots \mathrm{S} / \mathrm{S} \cdots \mathrm{H}$ contacts labeled 1 in Fig. 3 are again dominant, appearing as two larger deep-red spots at the upper (around $\mathrm{H} 4 \mathrm{~A}$ atom) and right (around S2 atom) sides in the $d_{\text {norm }}$ surface (left) attributed to strongest N4-H4A $\cdots \mathrm{S} 2$ hydrogen bonds. The smaller red spot labeled 1 at right is associated to weaker $\mathrm{C} 5-\mathrm{H} 5 \cdots \mathrm{S} 1$ hydrogen bonds. The former interactions are also observed as a sharp spike at the acceptor region in FP with short $\left(d_{\mathrm{e}}+d_{\mathrm{i}}\right) \cong 2.5 \AA$ and higher contribution of $22.4 \%$ to the total Hirshfeld surface, in comparison with a sharp spike at the donor region representing $\mathrm{H} 5 \cdots \mathrm{S} 1$ 


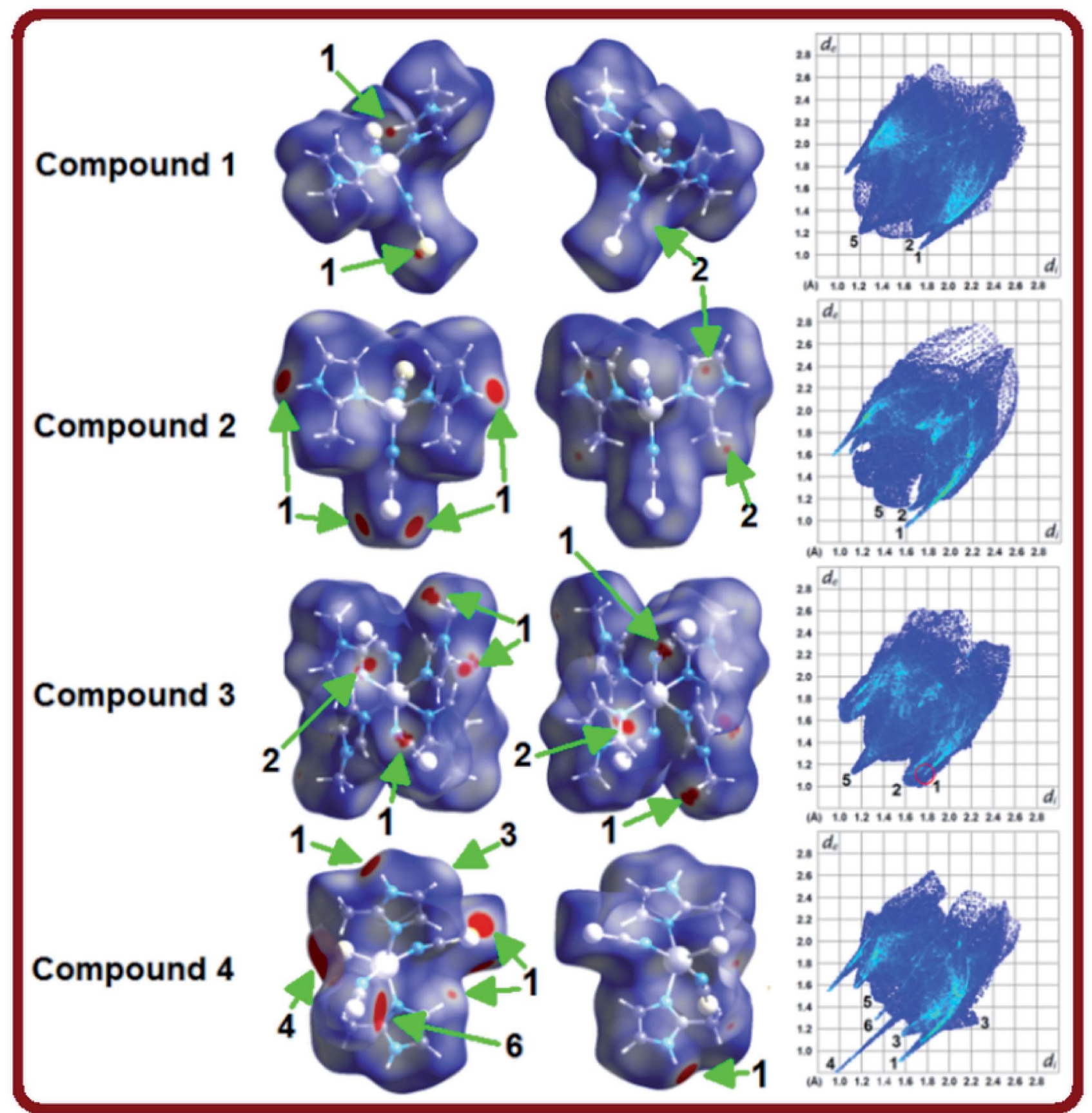

Fig. 3 Views of the Hirshfeld surfaces of compounds 1-4 (columns 1-2) mapped with $d_{\text {norm }}$ in two orientations: front view and back view (180 ${ }^{\circ}$ rotated around the vertical axis of the plot), and full 2D-fingerprint plots (column 3 ) derived from the surfaces. Close contacts are labeled as follows: (1) $\mathrm{S} \cdots \mathrm{H}$, (2) $\mathrm{C} \cdots \mathrm{H}$, (3) $\mathrm{N} \cdots \mathrm{H}$, (4) $\mathrm{C} \cdots \mathrm{S}$, (5) $\mathrm{H} \cdots \mathrm{H}$ and (6) $\mathrm{Cd} \cdots \mathrm{S}$.

contacts, and minor contribution of $8.8 \%$. The presence of point-to-face $\mathrm{C}-\mathrm{H} \cdots \pi$ interactions in the crystal assembly of this polymeric Cd complex is evident in shape index surface (Fig. 5c).

The white spot labeled 3 in the $d_{\text {norm }}$ map show weak $\mathrm{H} \cdots \mathrm{N} /$ $\mathrm{N} \cdots \mathrm{H}$ contacts attributed to $\mathrm{C} 4-\mathrm{H} 4 \cdots \mathrm{N} 2$ hydrogen bonds, which are viewed as a pair of wings at $\left(d_{\mathrm{e}}+d_{\mathrm{i}}\right) \cong 2.8 \AA$ in FP with notable contribution of $16.6 \%$ to the Hirshfeld surface area. The broad peak labeled 5 in FP is characteristic of $\mathrm{H} \cdots \mathrm{H}$ interactions providing a significant contribution of $21.2 \%$. It is worthwhile to indicate that the large deep-red spots labeled 4 (at left) and 6 in $d_{\text {norm }}$ surface of structure 4 represent inter-atomic $\mathrm{C} \cdots \mathrm{S} / \mathrm{S} \cdots \mathrm{C}$ $(4.3 \%)$ and $\mathrm{Cd} \cdots \mathrm{S} / \mathrm{S} \cdots \mathrm{Cd}(1.4 \%)$ contacts, respectively, connecting two monomeric species (see Fig. S4, ESI $\dagger$ ).

3.2.1. Enrichment ratio. To investigate the likelihood of occurrence of intermolecular $\mathrm{X} \cdots \mathrm{Y}$ contacts, the enrichment ratios $\left(E_{\mathrm{XY}}\right)$ in crystals ${ }^{39}$ of complexes 1-4 have been calculated and compared to those for related halogen-bonded dichloro- 


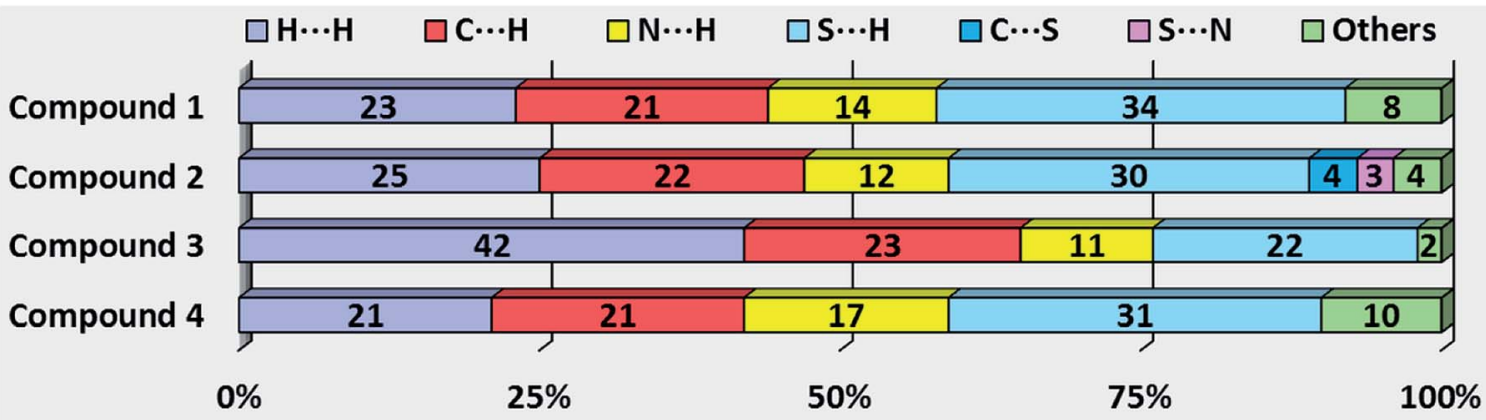

Fig. 4 Relative contributions of the main intermolecular contacts to the Hirshfeld surface area in compounds 1-4.

bis(1-methylimidazole)zinc(II), dibromo-bis(2-methylimidazole) cadmium(II)monohydrate, and bis(1-methylimidazole)-di-( $\mu 2-$ bromo)cadmium(II) complexes previously reported (labelled here as $\mathbf{5 - 7}$, respectively $)^{40}$. $E_{\mathrm{XY}}$ is defined as the ratio between the proportion of actual contacts $C_{\mathrm{XY}}$ in the crystal, and the theoretical proportion of random contacts $R_{\mathrm{XY}}$. The proportion $S_{\mathrm{X}}$ of different chemical species on the molecular surface is obtained from $C_{\mathrm{XX}}$ and $C_{\mathrm{XY}}$ values. The random contacts $R_{\mathrm{XY}}$ values are calculated from the corresponding $S_{\mathrm{X}}$ and $S_{\mathrm{Y}}$ proportions by using of probability products. An $E_{\mathrm{XY}}$ value larger than unity for a given $\mathrm{X} \cdots \mathrm{Y}$ pair indicates that these contacts are over-represented in the crystal packing when compared to equiprobable contacts computed from the chemical composition on the Hirshfeld surface. The chemical species that tend to avoid contacts are associated with $E_{\mathrm{XY}}$ values lower than unity.

The $E_{\mathrm{XY}}$ values for all the six complexes are listed in Table 5, while complete information is provided in Table S1 given as ESI. $\dagger$ The largest contributions to the Hirshfeld surfaces are from $\mathrm{S} \cdots \mathrm{H} / \mathrm{H} \cdots \mathrm{S}, \mathrm{N} \cdots \mathrm{H} / \mathrm{H} \cdots \mathrm{N}$ and $\mathrm{C} \cdots \mathrm{H} / \mathrm{H} \cdots \mathrm{C}$ contacts, and their ER values (1.11-1.54) are significantly higher than unity for compounds 1-4, showing high propensity to form $\mathrm{C}-\mathrm{H} \cdots \mathrm{S}$ and $\mathrm{C}-\mathrm{H} \cdots \mathrm{N}$ hydrogen bonds, as well as $\mathrm{C}-\mathrm{H} \cdots \pi$ interactions. The corresponding ER values (0.98-1.13) for related structures 5-7 are smaller than those for structures 1-4 indicating that the replacement of thiocyanate by halogen ligand in the three complexes decreases the propensity to form $\mathrm{X} \cdots \mathrm{H}(\mathrm{X}=\mathrm{N}, \mathrm{C})$ contacts, apart from $\mathrm{S} \cdots \mathrm{H}$ contacts which evidently disappear as expected.

It is also observed similar $E_{\mathrm{XY}}$ values from the three abovementioned contacts in compounds 3 and $\mathbf{4}$, whereas the likelihood of $\mathrm{N} \cdots \mathrm{H} / \mathrm{H} \cdots \mathrm{N}$ contacts $\left(E_{\mathrm{NH}}=1.11\right)$ is reduced in compound 2 related to those for compounds 3 (1.28) and 4 (1.46). This difference is presumably attributed to the existence of nitrogen atoms which are also involved in enriched $\mathrm{N} \cdots \mathrm{S} / \mathrm{S} \cdots$ $\mathrm{N}$ contacts for structure 2 as reflected by its relatively high $E_{\mathrm{NS}}$ value of 0.89 . On the other hand, the slightly high likelihood to form $\mathrm{C} \cdots \mathrm{S}$ contacts in compounds $2\left(E_{\mathrm{CS}}=0.74\right)$ and $\mathbf{4}\left(E_{\mathrm{CS}}=\right.$ 0.83 ) is due to higher proportion of sulfur (around 19.2\%) on the corresponding molecular surfaces, in comparison to $11.3 \%$ for structure.

ER values close to, but slightly less than unity, for the $\mathrm{H}^{\cdots} \mathrm{H}$ contacts are in accordance with the highest proportion $S_{\mathrm{H}}$ of hydrogen atoms (55.9-69.7\%) at the molecular surfaces, indicating a significant contribution from dispersive forces in the crystal packing of most of structures. The likelihood to form $\mathrm{H} \cdots \mathrm{H}$ contacts in the polymeric $\mathrm{Cd}(\mathrm{II})$ complexes mediated by thiocyanate (4) and halogen (7) ions is lowest $\left(E_{\mathrm{HH}}=0.68\right)$ for the former and highest for compound $7\left(E_{\mathrm{HH}}=1.02\right)$, consistent with the smallest $\left(C_{\mathrm{HH}}=21.4\right)$ and longest $\left(C_{\mathrm{HH}}=43.5\right)$ contact surfaces, respectively, as showed in Table S1, ESI. $\dagger$

The propensity of imidazole rings to form $\pi \cdots \pi$ stacking interactions is much more extensive in compounds $\mathbf{6}$ and 7 as reflected by the highly increased $E_{\mathrm{CC}}$ values of 2.67 and 3.33,

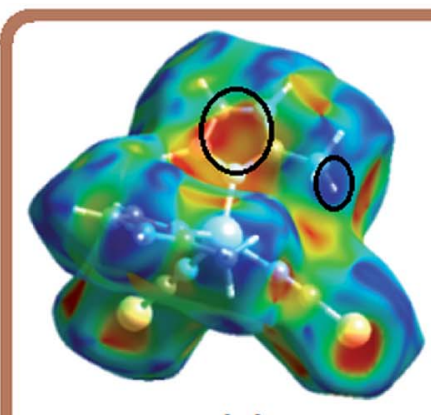

(a)

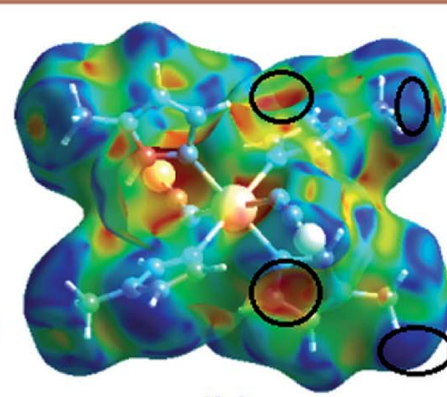

(b)

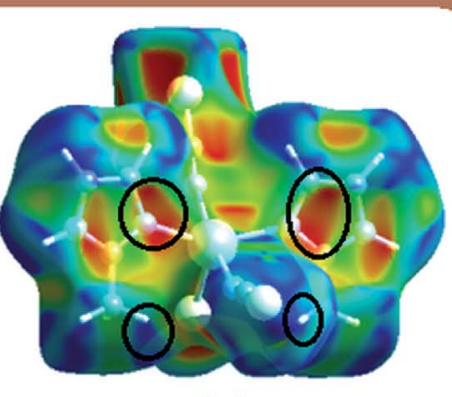

(c)

Fig. 5 Hirshfeld surfaces mapped over shape index for compounds 2-4. 
Table 5 Enrichment ratios $E_{X Y}$ of the main intermolecular interactions for complexes $1-7^{a}$

\begin{tabular}{llllllllll}
\hline & \multicolumn{3}{c}{ SCN-bonded } & & & & \multicolumn{2}{c}{ Halogen-bonded } \\
\cline { 2 - 4 } Interaction & $\mathbf{1}$ & $\mathbf{2}$ & $\mathbf{3}$ & $\mathbf{4}$ & & $\mathbf{5}$ & $\mathbf{6}$ & 7 \\
\hline $\mathrm{H} \cdots \mathrm{H}$ & 0.70 & 0.76 & 0.86 & 0.68 & 0.90 & 0.85 & 1.02 \\
$\mathrm{C} \cdots \mathrm{H} / \mathrm{H} \cdots \mathrm{C}$ & 1.25 & 1.39 & 1.29 & 1.41 & 1.00 & 1.04 & 0.98 \\
$\mathrm{~N} \cdots \mathrm{H} / \mathrm{H} \cdots \mathrm{N}$ & 1.34 & 1.11 & 1.28 & 1.46 & 1.04 & 1.13 & 1.11 \\
$\mathrm{~S} \cdots \mathrm{H} / \mathrm{H} \cdots \mathrm{S}$ & 1.54 & 1.39 & 1.38 & 1.45 & - & - & - \\
$\mathrm{O} \cdots \mathrm{H} / \mathrm{H} \cdots \mathrm{O}$ & - & - & - & - & - & 1.44 & - \\
$\mathrm{Cl} \cdots \mathrm{H} / \mathrm{H} \cdots \mathrm{Cl}$ & - & - & - & - & 1.37 & - & - \\
$\mathrm{Br} \cdots \mathrm{H} / \mathrm{H} \cdots \mathrm{Br}$ & - & - & - & - & - & 1.46 & 1.12 \\
$\mathrm{C} \cdots \mathrm{C}$ & 0.76 & 0.25 & 0.63 & 0.00 & 1.86 & 2.67 & 3.33 \\
$\mathrm{C} \cdots \mathrm{S} / \mathrm{S} \cdots \mathrm{C}$ & - & 0.74 & - & 0.83 & - & - & - \\
$\mathrm{N} \cdots \mathrm{S} / \mathrm{S} \cdots \mathrm{N}$ & 0.44 & 0.89 & - & - & - & - & - \\
$\mathrm{Cl} \cdots \mathrm{C} / \mathrm{C} \cdots \mathrm{Cl}$ & - & - & - & - & 0.53 & - & - \\
$\mathrm{C} \cdots \mathrm{N} / \mathrm{N} \cdots \mathrm{C}$ & 1.04 & - & - & - & - & - & 1.25
\end{tabular}

${ }^{a} E_{\mathrm{XY}}$ values for random contacts $R_{\mathrm{XY}}$ lower than $0.6 \%$ (Table S1, ESI) were not calculated, as they are not meaningful.

respectively, which are associated to $\mathrm{C} \cdots \mathrm{C}$ contacts according to the literature. ${ }^{19,38}$ These values explain the relatively low tendency observed for $\mathrm{C} \cdot \mathrm{H}$ contacts in the two $\mathrm{Cd}(\mathrm{II})$ halogencomplexes $\left(E_{\mathrm{CH}}=1.04\right.$ for 6 , and 0.98 for 7 ) when compared to remaining structures $\left(E_{\mathrm{CH}}=1.29-1.41\right)$, due to both $\mathrm{C} \cdots \mathrm{C}$ and $\mathrm{C} \cdots \mathrm{H}$ contacts are presumably in competition. ${ }^{\mathbf{4 1}}$ However, the $E_{\mathrm{CC}}$ value (1.86) is greatest than unity in compound 5 showing notable likelihood to form $\mathrm{C} \cdots \mathrm{C}$ contacts, but remarkably lower than those above indicated for $\mathbf{6}$ and 7, despite the very similar $E_{\mathrm{CH}}$ values we found in the three halogen-bonded complexes. According to crystal structure of $\mathbf{5}$, imidazole carbon atoms also weakly interact with chloride atoms $[\mathrm{Cl} 1 \cdots \mathrm{C} 21=3.510(3), \mathrm{Cl} 2 \cdots$ $\mathrm{C} 23=3.615(3) \AA]$, and though we obtained a relative low propensity to form $\mathrm{Cl} \cdots \mathrm{C}$ contacts $\left(E_{\mathrm{ClC}}=0.53\right)$, it may be enough to explain the reduced $E_{\mathrm{CC}}$ value. The absence of significant $\pi \cdots \pi$ stacking for compounds $\mathbf{1 - 4}$ is reflected in $E_{\mathrm{CC}}$ values lower than 0.63 (Table 5).

\subsection{Vibrational results}

The solid state IR and Raman spectra for all complexes (Fig. 6a and $b$, respectively) are consistent with their crystal structures. The assignment of the bands observed in the IR and Raman spectra are shown in the ESI. $\uparrow$ The assignment of the bands referred to the thiocyanate moiety is shown in Table 6. The spectra of 1-4 complexes show strong intensity bands in the $3147-3111 \mathrm{~cm}^{-1}$ spectral range which are attributed to $\mathrm{C}-\mathrm{H}$ stretching modes of the imidazole ring. These particular frequencies are slightly shifted because of the presence of intermolecular $\mathrm{C}-\mathrm{H} \cdots \pi$ interactions, as was discussed in the analysis of the crystal structures. The absorption bands of the $\nu_{\mathrm{a}}\left(\mathrm{CH}_{3}\right)$ and $\nu_{\mathrm{s}}\left(\mathrm{CH}_{3}\right)$ group in the complexes are observed in the frequency range $2984-2933 \mathrm{~cm}^{-1}$, and are blue-shifted as compared with the free ligand. The vibrations of $\mathrm{C}-\mathrm{N}$ and $\mathrm{C}-\mathrm{C}$ bonds of the imidazole ring generally appear coupled and can be observed in the $1671-1495 \mathrm{~cm}^{-1}$ range in the complexes spectra (see Tables S2 and S3, ESI $\dagger$ ). a)

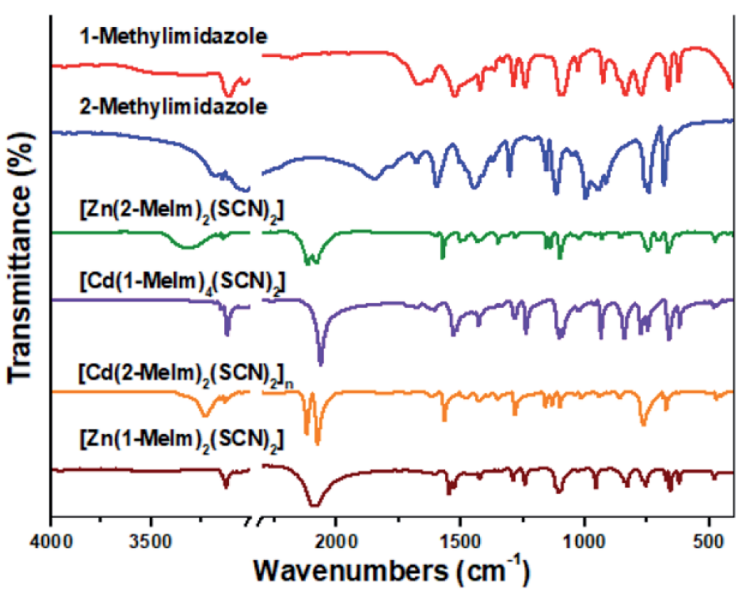

b)

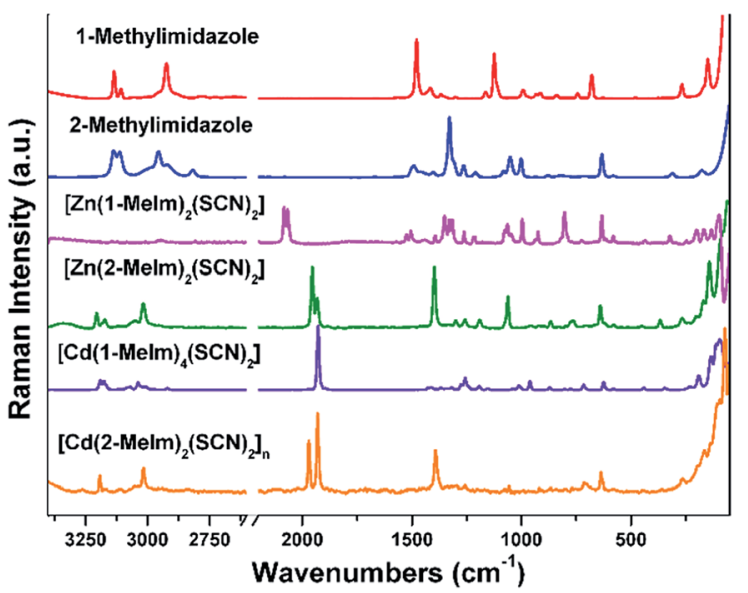

Fig. 6 (a) IR and (b) Raman spectra of 1-methylimidazole, 2-methylimidazole and their metal complexes.

The IR spectra of 1-3 monomeric complexes show two absorption bands in the $2100-2066 \mathrm{~cm}^{-1}$ range, assignable to the $\mathrm{CN}$ stretching mode of the thiocyanate moiety. In the complexes, these vibrations are below $2100 \mathrm{~cm}^{-1}$ hence suggesting the presence of terminal SCN group bounded through the $\mathrm{N}$ atom to the metal center. ${ }^{42}$ The $\mathrm{CN}$ stretching mode appears split, the spectral signature of not equivalent NCS groups. Thus, the band corresponding to the $\mathrm{C}=\mathrm{S}$ stretching mode appears as doublets in the $769-747 \mathrm{~cm}^{-1}$ frequency

Table 6 Infrared bands (in $\mathrm{cm}^{-1}$ ) corresponding to the SCN moiety for complexes 1-4

\begin{tabular}{llll}
\hline Complex & $\nu(\mathrm{CN})$ & $\nu(\mathrm{CS})$ & $\delta(\mathrm{NCS})$ \\
\hline \multirow{1}{*}{2098} & 768 & 478 \\
& 2083 & 753 & 473 \\
2 & 2100 & 757 & 478 \\
& 2077 & 747 & 470 \\
3 & 2083 & 769 & 473 \\
& 2066 & 764 & 464 \\
$\mathbf{4}$ & 2119 & 770 & 469 \\
& 2076 & 765 & 451
\end{tabular}


range. The bands observed between 478 and $464 \mathrm{~cm}^{-1}$ in the IR spectra of complexes 1-3 are assigned to the $\delta(\mathrm{NCS})$ bending mode and correspond to a N-bonded NCS group. ${ }^{42}$ The IR spectra of the polymeric complex 4 show two intense absorption bands at 2119 and $2076 \mathrm{~cm}^{-1}$. The high value of the $\mathrm{CN}$ stretching mode for this complex is consistent with either Sbonding or N,S-bridging mode (bands expected near $2100 \mathrm{~cm}^{-1}$ ). The bands corresponding to the CS stretching mode appear as doublets at 770 and $765 \mathrm{~cm}^{-1}$, confirming that we are dealing with $\mathrm{N}$-bonded $\left(860-760 \mathrm{~cm}^{-1}\right)$ rather than $\mathrm{S}$ bonded (720-690 $\left.\mathrm{cm}^{-1}\right)$ thiocyanate complexes. ${ }^{42}$

\subsection{Thermal studies of compounds 1-4}

TGA and DTA were used to investigate the thermal stability and the decomposition process of complexes 1-4. The curves for the thermal decomposition of complexes 1-4 are shown in Fig. S5S8, ESI. $\dagger$ The thermal behavior of all the complexes is similar. They decompose in two consecutive steps. The first one corresponds to the removal of 2 molecules of methylimidazole to form $\mathrm{Zn}(\mathrm{SCN})_{2}$ (exp. mass loss: $47.0 \%$, theoretical: $47.5 \%$ ), in agreement with the endothermic peaks located at 350 and $375{ }^{\circ} \mathrm{C}$ in the DTA curves of $\mathbf{1}$ and 2 , respectively. The second step finishes at $750{ }^{\circ} \mathrm{C}$, with a mass loss of $76.0 \%$ for 1 and 2 and it corresponds to the evolution of thiocyanate groups to form $\mathrm{ZnO}$ as final product. The observed mass loss is in very good agreement with the calculated ones (see Table S4, ESI $\dagger$ ). Similar results were obtained for $\mathrm{Cd}(\mathrm{II})$ complexes.

The endothermic peaks located at 100, 167, 94 and $144{ }^{\circ} \mathrm{C}$ in the DTA curves (without mass loss in TGA) are attributed to the melting point of complexes 1, 2, 3 and 4, respectively.

\subsection{Electronic spectra and photoluminescence properties}

The electronic spectra of the ligands and its complexes were collected in acetonitrile (Fig. S9, ESI $\dagger$ ). The spectra of $\mathrm{Zn}$ (II) and Cd(II) complexes with $\mathrm{d}^{10}$ electronic configuration do not present any $d-d$ electronic transitions. The intense band at $240 \mathrm{~nm}$ in the electronic spectra of the ligands and complexes are attributed to intra-ligand $\pi \rightarrow \pi^{*}$ transitions. All complexes display bands in the region 380-550 $\mathrm{nm}$ attributable to charge transfer (CT) from the metal to ligand (M-L) transitions expected for these types of systems. ${ }^{43}$

Photoluminescence properties of 1-MeIm, 2-MeIm and 1-4 complexes have been studied in acetonitrile solution $\left(1 \times 10^{-3}\right.$ M). The emission spectra of 1-MeIm, 2-MeIm and their $\mathrm{Zn}$ (II) and Cd(II) complexes are shown in Fig. 7(a) and (b). The main chromosphere studied in these compounds is the aromatic imidazole ring. The free ligands display the main emission peaks at 404 and $327 \mathrm{~nm}\left(\lambda_{\text {exc }}=270 \mathrm{~nm}\right)$ for 1-MeIm and at 327 and $355 \mathrm{~nm}$ for 2-MeIm. The emission bands of the free ligands are probably assigned to $\pi \rightarrow \pi^{*}$ or $\mathrm{n} \rightarrow \pi^{*}$ transitions. $^{\mathbf{4 4}}$

As shown in Fig. 7a, the emission spectra of complexes 1 and 3 display two similar bands located at 306 and $360 \mathrm{~nm}\left(\lambda_{\text {exc }}=\right.$ $270 \mathrm{~nm}$ ), which suggest that the emission properties are closely related. Interestingly, the positions of the first emission bands of the complexes are hypsochromically shifted compared with the free ligand. The observed blue shift could be explained by considering that the excited state originating from $\mathrm{Zn}$ (II) and Cd(II) complexes are mainly intra-ligand transitions modified by metal coordination. A similar behavior was observed for 2MeIm and its $\mathrm{Zn}$ (II) and $\mathrm{Cd}(\mathrm{II})$ thiocyanate complexes. The enhancement of the photoluminescence observed in the complexes 1-4 with respect to the free ligands are attributed to coordination effect of ligands to $\mathrm{Zn}$ (II) and $\mathrm{Cd}(\mathrm{II})$ ions, which increases the rigidity of the ligand and reduce the loss of energy by non-radiative decay pathways. ${ }^{45}$ The emission band observed at around $360 \mathrm{~nm}$ in complexes 1-4 may be assigned to ligand to metal charge transfer (MLCT). ${ }^{46}$ Average luminescence lifetimes $(\tau)$ were measured for both ligands and complexes 1-4. For the emission band at around $360 \mathrm{~nm}$ in complexes 1-4, the average luminescence lifetime of 11.0 ns were measured at room temperature, much longer than those observed in free ligands. The decay of the luminescence intensity integrated over the whole spectral range of the ligands and complexes 1-4 are shown in Fig. S10, ESI. $\dagger$

It has been reported that the $\pi \cdots \pi$ stacking occurring between methylimidazole rings may control the luminescence

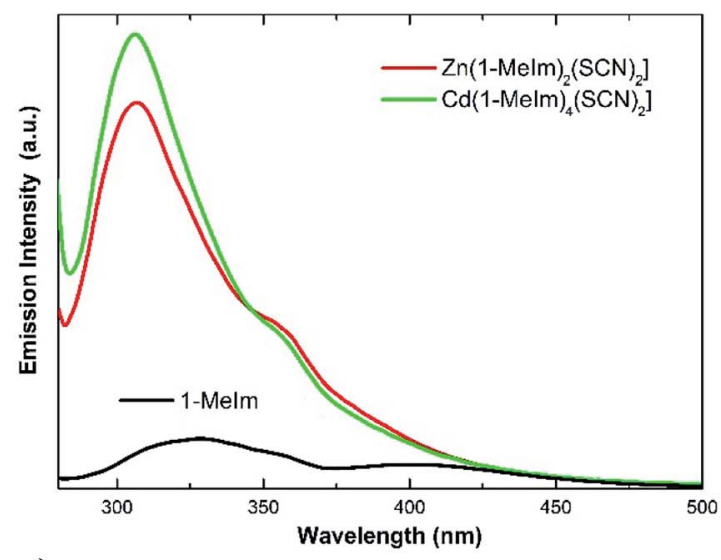

a)

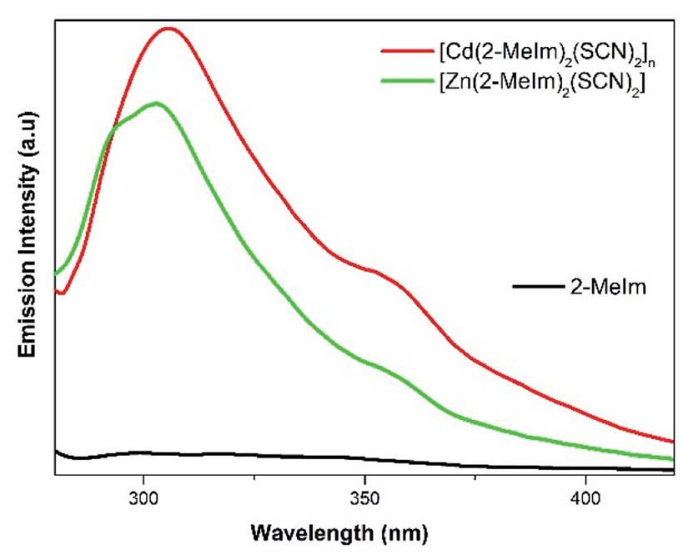

b)

Fig. 7 Emission spectra of (a) 1-Melm free ligand and its $\mathrm{Zn}(I)$ and $\mathrm{Cd}(\mathrm{I})$ thiocyanate complexes; (b) 2-Melm and its complexes. 
efficiency of metal complexes in both solid and solution state. ${ }^{2}$ In the series of compounds $\mathbf{1 - 4}$, the inter-centroid $\mathrm{Cg} \cdots \mathrm{Cg}$ distances (4.212-4.644 $\AA$ ) are longer than the typical 3.3-3.8 for face-to-face $\pi \cdots \pi$ interactions, ${ }^{29}$ and the observed values have an unclear relationship with the fluorescence intensities (see Fig. 7). Instead, we have found an interesting correlation between fluorescence and the $\mathrm{C}-\mathrm{H} \cdots \pi$ interactions. In compound 1, the $\mathrm{H} 24 \mathrm{~A} \cdots \mathrm{Cg}$ value of $3.543 \AA$ is out the limit $(\mathrm{H} \cdots \mathrm{Cg}<3.0 \AA)$ set by PLATON, ${ }^{15}$ and hence the $\mathrm{C}-\mathrm{H} \cdots \pi$ interaction is not significant. However, in structures 2-4 with significant $\mathrm{C}-\mathrm{H} \cdots \pi$ contacts (Table 4 ), we have found that with lower $\mathrm{H} \cdots \mathrm{Cg}$ distances (stronger contacts), higher fluorescence intensities are obtained, which reveal that at least in the three mentioned structures the existence of $\mathrm{C}-\mathrm{H} \cdots \pi$ interactions may be responsible for fluorescence. In comparison to structures 2 and 4 with large $\mathrm{Cg} \cdots \mathrm{Cg}$ distances of $4.396(1)$ and 4.644(1) $\AA$, respectively, the higher luminescence intensity in $\mathbf{1}$ may be due to the presence of a stronger $\pi \cdots \pi$ contact (shorter $\mathrm{Cg} \cdots \mathrm{Cg}$ distance $=4.220(1) \AA) .{ }^{47}$

\section{Conclusions}

Four new thiocyanate-Zn(II) and Cd(II) complexes with 1-methylimidazole (1-MeIm) and 2-methylimidazole (2-MeIm), namely, $\mathrm{Zn}(1-\mathrm{MeIm})_{2}(\mathrm{SCN})_{2}$ (1), Zn(2-MeIm $)_{2}(\mathrm{SCN})_{2}$ (2), Cd(1-MeIm $)_{4}(-$ $\mathrm{SCN})_{2}(3)$ and $\left[\mathrm{Cd}(2-\mathrm{MeIm})_{2}(\mathrm{SCN})_{2}\right]_{n}(4)$, have been synthesized and characterized by IR, Raman and UV-Vis spectroscopy and thermal analysis. The crystal structures of complexes 1-4 have been solved by single-crystal X-ray diffraction methods. The 3D Hirshfeld surface analysis and 2D fingerprint maps analysis have shown that weak intermolecular $\mathrm{S} \cdots \mathrm{H}$ hydrogen bonds and $\mathrm{C}-\mathrm{H} \cdots \pi$ stacking interactions play dominant roles in stabilizing the lattice of the three structures, revealing also different packing modes. The enrichment ratios of different intermolecular interactions in the thiocyanate-bonded complexes when compared for similar halogen-bonded complexes lead us to conclude that the substitution of halogen by thiocyanate in the coordination sphere increases the tendency to form $\mathrm{C} \cdots \mathrm{H}$ contacts attributed to $\mathrm{C}-\mathrm{H} \cdots \pi$ interactions. In addition, the luminescent properties of the free ligands and complexes 1-4 were studied in acetonitrile solution at room temperature. The emissions observed in the spectra of complexes were ascribed to the intra-ligand transitions and ligand-to-metal charge transfer. This work reveals that the C$\mathrm{H} \cdots \pi$ and $\pi \cdots \pi$ intermolecular interactions are also responsible of the fluorescence observed.

\section{Conflicts of interest}

There are no conflicts of interest to declare.

\section{Acknowledgements}

This work was supported by ANPCyT (PICT 2016-0226 and PICT 2013-0697), SCAIT-UNT (PIUNT D542/2), CONICET (PIP 11220130100651CO and PIP 11220150100002CO) and UNLP (Grant 11/X709) of Argentina. A. D. S. thanks CONICET for the doctoral fellowship. G. A. E and O. E. P. are Research Fellows of CONICET. R. E. C. thanks support from Consejo Nacional de Investigaciones Científicas y Técnicas (CONICET), PIP \# 11220120100360, the Agencia Nacional de Promoción Científica y Tecnológica (ANPCyT), PICT-2013-2149 and the Secretaría de Ciencia y Tecnología de la Universidad Nacional de Córdoba (SECyT-UNC), Project 203/14. We thank Lic. Alejandro Menzaque for taking the PXRD and TGA-DTA data.

\section{References}

1 S. Qiu, M. Xue and G. Zhu, Chem. Soc. Rev., 2014, 43, 61166140 .

2 L. E. Kreno, K. Leong, O. K. Farha, M. Allendorf, R. P. Van Duyne and J. T. Kupp, Chem. Rev., 2012, 112, 1105-1125.

3 J. Rocha, L. D. Carlos, F. A. Almeida Paz and D. Ananias, Chem. Soc. Rev., 2011, 40, 926-940.

4 O. R. Evans and W. Lin, Chem. Mater., 2001, 13, 3009-3017. 5 J. L. C. Rowsell and O. M. Yaghi, Angew. Chem., Int. Ed., 2005, 44, 4670-4679.

6 N. Upadhayay, Chem. Sci. Trans., 2013, 2, 455-460.

7 (a) F. A. Mautner, M. Scherzer, C. Berger, R. C. Fischer, R. Vicente and S. S. Massoud, Polyhedron, 2015, 85, 20-26; (b) S. S. Massoud, M. Dubin, A. E. Guilbeau, M. Spell, R. Vicente, P. Wilfling, R. C. Fischer and F. A. Mautner, Polyhedron, 2014, 78, 135-140; (c) H. Golchoubian, S. Koohzad, M. Ramzani and D. Farmanzadeh, Polyhedron, 2013, 51, 1-9; (d) F. A. Mautner, M. Scherzer, C. Berger, R. C. Fischer, R. Vicente and S. S. Massoud, Polyhedron, 2012, 31, 601-606.

8 K. S. Banu, S. Mondal, A. Guha, S. Das, T. Chattopadhyay, E. Suresh, E. Zangrando and D. Das, Polyhedron, 2011, 30, 163-168.

9 (a) N. Sarkar, K. Harms, A. Frontera and S. Chattopadhyay, New J. Chem., 2017, 41, 8053-8065; (b) S. Roy, M. G. B. Drew, A. Bauzá, A. Frontera and S. Chattopadhyay, Dalton Trans., 2017, 46, 5384-5397; (c) S. Roy, A. Bhattacharyya, S. Herrero, R. González-Prieto, A. Frontera and S. Chattopadhyay, ChemistrySelect, 2017, 2, 6535-6543.

10 R. M. Kumar, M. Elango, R. Parthasarathi, D. Vijay and V. Subramanian, J. Chem. Sci., 2012, 124, 193-202.

11 (a) G. R. Desiraju, Acc. Chem. Res., 2002, 35, 565; (b) K. Biradha, Cryst. Growth Des., 2012, 12, 5834.

12 P. Hobza and Z. Havlas, Chem. Rev., 2000, 100, 4253.

13 S. K. Seth, I. Saha, C. Estarellas, A. Frontera, T. Kar and S. Mukhopadhyay, Cryst. Growth Des., 2011, 11, 3250-3265.

14 A. Saeed, M. Bolte, M. F. Erben and H. Pérez, CrystEngComm, 2015, 17, 7551-7563.

15 M. Montazerozohori, A. Masoudiasl and T. Doert, Inorg. Chim. Acta, 2016, 443, 207-217.

16 M. Owczarek, I. Majerz and R. Jakubas, CrystEngComm, 2014, 16, 7638-7648.

17 C. Jelsch, K. Ejsmont and L. Huder, IUCrJ, 2014, 1, 119-128. 18 S. Soudani, V. Ferretti, C. Jelsch, F. Lefebvre and C. B. Nasr, J. Solid State Chem., 2016, 237, 7-13. 
19 CrysAlisPro, Oxford Diffraction Ltd., version 1.171.33.48 (release 15-09-2009 CrysAlis171.NET).

20 G. M. Sheldrick, Acta Crystallogr., 2008, A64, 112-122.

21 A. Spek, Acta Crystallogr., 2009, D65, 148-155.

22 O. V. Dolomanov, L. J. Bourhis, R. J. Gildea, J. A. K. Howard and H. Puschmann, J. Appl. Crystallogr., 2009, 42, 339-341.

23 C. F. Macrae, I. J. Bruno, J. A. Chisholm, P. R. Edgington, P. McCabe, E. Pidcock, L. Rodriguez Monge, R. Taylor, J. van de Streek and P. A. Wood, J. Appl. Crystallogr., 2008, 41, 466-470.

24 (a) J. J. McKinnon, M. A. Spackman and A. S. Mitchell, Acta Crystallogr., 2004, B60, 627-668; (b) Y. H. Luo, C. Chen, D. L. Hong, X. T. He, J. W. Wang and B. W. Sun, J. Phys. Chem. Lett., 2018, 9, 2158-2163.

25 J. J. McKinnon, D. Jayatilaka and M. A. Spackman, Chem. Commun., 2007, 3814-3816.

26 M. A. Spackman and D. Jayatilaka, CrystEngComm, 2009, 11, 19-32.

27 M. A. Spackman, Chem. Rev., 1992, 92, 1769-1797.

28 S. K. Wolff, D. J. Grimwood, J. J. McKinnon, M. J. Turner, D. Jayatilaka and M. A. Spackman, CrystalExplorer (Version 3.0), University of Western Australia, 2012.

29 M. A. Spackman, Phys. Scr., 2013, 87, 048103.

30 L. Yang, D. R. Powell and R. P. Houser, Dalton Trans., 2007, 955.

31 M. W. Schmidt, K. K. Baldridge, J. A. Boatz, S. T. Elbert, M. S. Gordon, J. H. Jensen, S. Koseki, N. Matsunaga, K. A. Nguyen, S. Su and T. L. Windus, J. Comput. Chem., 1993, 14, 1347.

32 (a) T. Steiner, Angew. Chem., Int. Ed., 2002, 41, 48-76; (b) G. A. Jeffrey, An Introduction to Hydrogen Bonding, Oxford University Press, Oxford, 1997.

33 M. Egli and S. Sarkhel, Acc. Chem. Res., 2007, 40, 197-205.

34 S. K. Seth, CrystEngComm, 2013, 15, 1772-1781.
35 (a) C. Janiak, S. Temizdemir, S. Dechert, W. Deck, F. Girgsdies, J. Heinze, M. J. Kolm, T. G. Scharmann and O. M. Zipffel, Eur. J. Inorg. Chem., 2000, 1229-1241; (b) C. Janiak, J. Chem. Soc., Dalton Trans., 2000, 3885-3896.

36 A. W. Addison, T. N. Rao, J. Reedijk, J. van Rijn and G. C. Verschoor, J. Chem. Soc., Dalton Trans., 1984, 13491356.

37 D. Bose, J. Banerjee, S. H. Rahaman, G. Mostafa, H.-K. Fun, R. D. Bailey Walsh, M. J. Zaworotko and B. K. Ghosh, Polyhedron, 2004, 23, 2045-2053.

38 E. Rozycka-Sokolowska, B. Marciniak, J. Ławeck, B. Bujnicki, J. Drabowicz and A. Rykowski, J. Sulfur Chem., 2013, 34, 651660.

39 S. Syed, M. M. Jotani, S. N. A. Halim and E. R. T. Tiekink, Acta Crystallogr., 2016, E72, 391-398.

40 A. Di Santo, G. A. Echeverría, O. E. Piro, H. Pérez, A. B. Altabef and D. M. Gil, J. Mol. Struct., 2017, 1134, 492503.

41 C. Jelsch, S. Soudani and C. B. Nasr, IUCrJ, 2015, 2, 327-340. 42 K. Nakamoto, Infrared and Raman Spectra of Inorganic and Coordination Compounds, Part B: Applications in Coordination, Organometallic, and Bioinorganic Chemistry, Wiley Interscience, New York, 5th edn, 1997.

43 Z. Leka, S. A. Gruji, Z. Tesic, S. Lukic, S. Skuban and S. Trifunovi, J. Serb. Chem. Soc., 2004, 69, 137-143.

44 D. F. Weng, Z. M. Wang and S. Gao, Chem. Soc. Rev., 2011, 40, 3157-3181.

45 R. Boča, Coord. Chem. Rev., 2004, 248, 757-815.

46 M. Saber and K. R. Dunbar, Chem. Commun., 2014, 50, 12266. 47 (a) G. Jin, R. Wang, Y. Xiu, Y. Yang and X. Meng, Synth. React. Inorg., Met.-Org., Nano-Met. Chem., 2012, 42, 596-602; (b) G. S. Kürkçüoğlu, O. Z. Yeşilel, I. Çaylı and O. Büyükgüngör, J. Inorg. Organomet. Polym., 2011, 21, 306315. 